\title{
PENGARUH LINGKUNGAN KERJA, KOMUNIKASI, KOMPETENSI \\ DAN KOMPENSASI TERHADAP KEPUASAN KERJA KARYAWAN \\ PABRIK SOGM PADA PT PERKEBUNAN MINANGA \\ OGAN REGION SUMSEL-LAMPUNG
}

\author{
Oleh : \\ Yopi Yunsepa \\ Sekolah Tinggi Ilmu Ekonomi (STIE) Dwi Dwisakti Baturaja \\ Email : yopizulhanapi@gmail.com
}

\begin{abstract}
Abstrak
Penelitian ini membahas tentang Pengaruh lingkungan kerja, komunikasi, kompetensi dan kompensasi terhadap kepuasan kerja karyawan pabrik sogm pada pt perkebunan minanga Ogan Region Sumsel-Lampung. Penelitian ini bertujuan untuk mengetahui pengaruh lingkungan kerja, komunikasi, kompetensi dan kompensasi terhadap kepuasan kerja karyawan pabrik SOGM PT Perkebunan Minanga Ogan Region Sumsel-Lampung baik secara bersama-sama maupun sendiri-sendiri. Penelitian ini dilakukan di Pabrik SOGM PT Perkebunan Minanga Ogan Region Sumsel-Lampung. Jumlah responden dalam penelitian ini sebanyak 159 orang. Tehnik pengumpulan data dalam penelitian ini adalah dengan cara kuesioner, wawancara dan dokumentasi. Data dianalisis dengan menggunakan model analisis regresi linier berganda. Hasil analisis dan pengujian hipotesis menunjukkan bahwa lingkungan kerja, komunikasi, kompetensi dan kompensasi secara bersama-sama dan parsial berpengaruh signifikan terhadap kepuasan kerja karyawan pabrik SOGM PT Minanga Ogan Region Sumsel-Lampung.

Penelitian ini menunjukkan bahwa karyawan pabrik SOGM PT Perkebunan Minanga Ogan Region Sumsel-Lampung telah merasakan kepuasan kerja dimana lingkungan kerja sudah cukup baik, sehingga karyawan dapat bekerja dengan baik pula. Komunikasi antar karyawan terjalin dengan sangat baik, ini membuktikan bahwa karyawan dapat bekerjasama dalam tim, begitu pula kompetensi yang tercipta dalam tim dan pemberian kompensasi oleh pihak perusahaan sudah sesuai.
\end{abstract}

Kata kunci: Lingkungan kerja, komunikasi, kompetensi, kompensasi dan kepuasan kerja karyawan

\section{PENDAHULUAN}

\section{A. Latar Belakang Penelitian}

Kepuasan kerja karyawan menjadi salah satu elemen penting dalam berjalannya suatu per-usahaan. Menurut Douglas (2000) menjelaskan bahwa perusahaan membutuhkan karyawan yang handal, mampu bekerja lebih baik dan lebih cepat, sehingga diperlukan karyawan yang mempunyai kinerja (job performance) yang tinggi untuk ditempatkan pada posisi yang diperlukan. Mokaya et al. (2013) menyatakan organisasi harus terus mengadakan perubahan kearah yang positif, karena tugasnya tidak hanya menarik staf yang tepat, akan tetapi juga harus menciptakan dan memperTahankan motivasi kerja, sehingga tercipta kepuasan kerja. 
PT Perkebunan Minanga Ogan Region Sumsel-Lampung merupakan perusahaan yang bergerak di bidang perindustrian minyak kelapa sawit mentah atau sering disebut CPO (Crude Palm Oil), dimana produksi sangatlah penting dalam mencapai tujuan perusahaan. Dalam mewujudkan tujuan perusahaan tersebut, perusahaan disini perlu memper-hatikan kepuasan kerja karyawan, jika kepuasan kerja sudah terwujud, maka akan memacu motivasi dan semangat kerja.

Berdasarkan pengamatan dan wawancara yang dilakukan dengan beberapa karyawan pabrik SOGM PT Perkebunan Minanga Ogan Region Sumsel-Lampung, dapat disimpulkan bahwa rendahnya kepuasan kerja karyawan dipengaruhi oleh kondisi lingkungan kerja, dimana kurang adanya penataan tempat kerja karyawan, sehingga kar-yawan kurang nyaman dalam melakukan pekerjaannya. Sirkulasi udara di tempat kerja kurang baik karena minimnya jumlah ventilasi. Penataan ruangan yang kurang baik, sehingga menyebabkan kurang optimalnya tugas karyawan administrasi, yang cendrung lamban menyelesaikan tugas-tugas mereka. Selain itu juga dekatnya jarak antara pabrik dengan kantor yang membuat suara menjadi bising, serta bau limbah yang menyengat hidung membuat suasana kerja menjadi tidak nyaman.

Berdasarkan uraian latar belakang tersebut diatas, maka dapat diajukan sebuah penelitian dengan judul

PENGARUH LINGKUNGAN KERJA, KOMUNIKASI, KOMPETENSI DAN KOMPENSASI TERHADAP KEPUASAN KERJA KARYAWAN PABRIK SOGM PADA PT PERKEBUNAN MINANGA OGAN REGION SUMSEL-LAMPUNG.

\section{B. Rumusan Masalah}

a. Apakah terdapat pengaruh lingkungan kerja, komunikasi, kompetensi dan kompensasi terhadap kepuasan kerja karyawan pabrik SOGM PT Perkebunan Minanga Ogan Region Sumsel-Lampung?

b. Apakah terdapat pengaruh lingkungan kerja, terhadap kepuasan kerja karyawan pabrik SOGM PT Perkebunan Minanga Ogan Region Sumsel-Lampung?

c. Apakah terdapat pengaruh komunikasi, terhadap kepuasan kerja karyawan pabrik SOGM PT Perkebunan Minanga Ogan Region Sumsel-Lampung?

d. Apakah terdapat pengaruh kompetensi, terhadap kepuasan kerja karyawan pabrik SOGM PT Perkebunan Minanga Ogan Region Sumsel-Lampung?

e. Apakah terdapat pengaruh kompensasi, terhadap kepuasan kerja karyawan pabrik SOGM PT Perkebunan Minanga Ogan Region Sumsel-Lampung?

\section{Tujuan Penelitian}

1. Untuk mengetahui dan membuktikan pengaruh variabel lingkungan kerja, komunikasi, kompetensi dan kompensasi terhadap kepuasan kerja karyawan pabrik SOGM PT Perkebunan Minanga Ogan Region Sumsel-Lampung.

2. Untuk mengetahui dan membuktikan pengaruh lingkungan kerja terhadap kepuasan kerja karyawan pabrik SOGM PT Perkebunan Minanga Ogan Region Sumsel-Lampung.

3. Untuk mengetahui dan membuktikan pengaruh komunikasi terhadap kepuasan kerja karyawan pabrik 
SOGM PT Perkebunan Minanga Ogan Region Sumsel-Lampung.

4. Untuk mengetahui dan membuktikan pengaruh kompetensi terhadap kepuasan kerja karyawan pabrik SOGM PT Perkebunan Minanga Ogan Region Sumsel-Lampung.

5. Untuk mengetahui dan membuktikan pengaruh kompensasi terhadap kepuasan kerja karyawan pabrik SOGM PT Perkebunan Minanga Ogan Region Sumsel-Lampung.

\section{KAJIAN PUSTAKA}

\section{A. Teori}

\section{1) Lingkungan Kerja}

Menurut Nitisemito (2002, p. 109) lingkungan kerja adalah segala sesuatu yang ada di lingkungan pekerja yang dapat mempengaruhi dirinya dalam menjalankan tugas yang dibebankan. Sedarmayanti (2001, p. 21) menyatakan bahwa secara garis besar, jenis lingkungan kerja terbagi menjadi dua yakni lingkungan kerja fisik dan lingkungan kerja non fisik.

\section{2) Komunikasi}

Komunikasi adalah proses penyampaian pikiran atau perasaan oleh seseorang kepada orang lain dengan menggunakan lambang-lambang yang bermakna bagi kedua pihak, dalam situasi yang tertentu komunikasi menggunakan media tertentu untuk merubah sikap atau tingkah laku seorang atau sejumlah orang sehingga ada efek tertentu yang diharapkan (Effendy, 2000, p. 13), sedangkan menurut Handoko, 2002, p. 30 komunikasi adalah proses pemindahan pengertian dalam bentuk gagasan, informasi dari seseorang ke orang lain. Tidak ada kelompok yang dapat eksis tanpa komunikasi, pentransferan makna di antara anggota-anggotanya. Hanya lewat pentransferan makna dari satu orang ke orang lain informasi dan gagasan dapat dihantarkan. Tetapi komunikasi itu lebih dari sekedar menanamkan makna tetapi harus juga dipahami (Robbins, 2002, p. 310).

\section{3) Kompetensi}

Kompetensi adalah suatu kemampuan untuk melaksanakan atau melakukan suatu pekerjaan atau tugas yang dilandasi atas keterampilan dan pengetahuan serta didukung oleh sikap kerja yang dituntut oleh pekerjaan tersebut. Dengan demikian, kompetensi menunjukkan keterampilan atau pengetahuan yang dicirikan oleh profesionalisme dalam suatu bidang tertentu sebagai sesuatu yang terpenting, sebagai unggulan bidang tersebut (Wibowo, 2013, p. 271).

\section{4) Kompensasi}

Dilihat dari cara pemberiannya, kompensasi dapat merupakan kompensasi langsung dan kompensasi tidak langsung. Kompensasi langsung merupakan kompensasi manajemen seperti upah dan gaji atau pay for performance, seperti insentif dan gain sharing. Sementara itu, kompensasi tidak langsung dapat berupa tunjangan atau jaminan keamanan dan kesehatan. (Wibowo, 2013, p. 290)

Manajemen kompensasi adalah salah satu fungsi penting dalam manajemen sumber daya manusia. Menurut Wibowo, 2013, p. 291 tujuan manajemen kompensasi adalah untuk membantu organisasi mencapai keberhasilan strategis sambil memastikan keadilan internal dan eksternal. Internal equity atau keadilan internal memastikan bahwa jabatan yang lebih menantang atau orang yang mempunyai kualifikasi lebih baik dalam 
organisasi dibayar lebih tinggi. Sementara itu, external equity atau keadilan eksternal menjamin bahwa pekerjaan mendapatkan kompensasi secara adil dalam perbandingan dengan pekerjaan yang sama di pasar tenaga kerja.

\section{5) Kepuasan Kerja Karyawan}

Dole dan Schroeder (2001) dalam Koesmono (2005), mengemukakan bahwa kepuasan kerja dapat didefinisikan sebagai perasaan dan reaksi individu terhadap lingkungan pekerjaannya. Lebih lanjut Koesmono (2005) mengemukakan bahwa kepuasan kerja merupakan penilaian, perasaan atau sikap seseorang atau karyawan terhadap pekerjaannya dan berhubungan dengan lingkungan kerja, jenis pekerjaan, kompensasi, hubungan antar teman kerja, hubungan sosial ditempat kerja dan sebagainya. Sehingga dapat dikatakan bahwa kepuasan kerja adalah dipenuhinya beberapa keinginan dan kebutuhannya melalui kegiatan kerja atau bekerja.

$$
\text { Robbins (2001, p. }
$$

mengemukakan bahwa kepuasan kerja adalah sebagai suatu sikap umum seorang individu terhadap pekerjaannya. Pekerjaan menuntut interaksi dengan rekan sekerja dan atasan, mengikuti aturan dan kebijakan organisasi, memenuhi standar kinerja, hidup pada kondisi kerja yang sering kurang dari ideal, dan hal serupa lainnya. Ini berarti penilaian (assesment) seorang karyawan terhadap puas atau tidak puasnya dia terhadap pekerjaan merupakan penjumlahan yang rumit dari sejumlah unsur pekerjaan yang diskrit (terbedakan dan terpisahkan satu sama lain).

\section{B. Penelitian Sebelumnya}

Tabel 1

Data Penelitian Sebelumnya dan Penelitian Sekarang

\begin{tabular}{|c|c|c|c|c|c|c|c|}
\hline No & Peneliti & Penelitian & Variabel & Metode & Hasil Penelitian & Persamaan & Perbedaan \\
\hline 1 & $\begin{array}{l}\text { I Gede } \\
\text { Diatmika } \\
\text { Paripurna } \\
(2012)\end{array}$ & $\begin{array}{l}\text { Pengaruh } \\
\text { Kepemimpinan, } \\
\text { Lingkungan Kerja } \\
\text { Dan Komunikasi } \\
\text { Terhadap Kepuasan } \\
\text { Kerja Karyawan. }\end{array}$ & $\begin{array}{l}\text { Kepemimpinan, } \\
\text { Lingkungan } \\
\text { Kerja, } \\
\text { Komunikasi, } \\
\text { Kepuasan Kerja } \\
\text { Karyawan. }\end{array}$ & $\begin{array}{l}\text { Regresi } \\
\text { linier } \\
\text { berganda }\end{array}$ & $\begin{array}{l}\text { Kepemimpinan, lingkungan kerja dan komunikasi } \\
\text { secara simultan dan parsial, dinilai berpengaruh secara } \\
\text { signifikan terhadap kepuasan kerja karyawan serta } \\
\text { variabel kepemimpinan berpengaruh dominan terhadap } \\
\text { kinerja karyawan, bila dibandingkan dengan kedua } \\
\text { variabel bebas lainnya. }\end{array}$ & $\begin{array}{l}\text { - Variabel } \\
\text { lingkungan } \\
\text { kerja dan } \\
\text { komunikasi } \\
\text { - Metode regresi } \\
\text { linier berganda }\end{array}$ & $\begin{array}{l}\text { Variabel } \\
\text { kepemimpinan } \\
\text { Tehnik } \\
\text { pengambilan } \\
\text { sampel dengan } \\
\text { metode sensus }\end{array}$ \\
\hline 2 & $\begin{array}{l}\text { Ni Putu Intan } \\
\text { Ratnasari dan } \\
\text { A.A Sagung } \\
\text { Kartika Dewi } \\
\text { (2013) }\end{array}$ & $\begin{array}{l}\text { Pengaruh Motivasi, } \\
\text { Lingkungan Kerja } \\
\text { Fisik Dan } \\
\text { Kepemimpinan } \\
\text { Terhadap Kepuasan } \\
\text { Kerja Karyawan. }\end{array}$ & $\begin{array}{l}\text { Motivasi, } \\
\text { Lingkungan } \\
\text { Kerja Fisik, } \\
\text { Kepemimpinan, } \\
\text { Kepuasan Kerja } \\
\text { Karyawan. }\end{array}$ & $\begin{array}{l}\text { Regresi } \\
\text { linier } \\
\text { berganda }\end{array}$ & 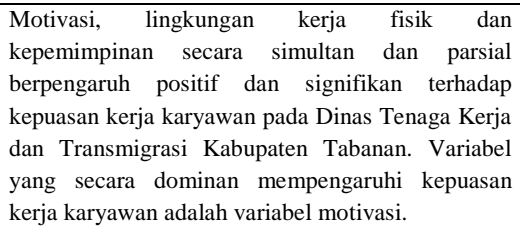 & $\begin{array}{l}\text { - Variabel } \\
\text { lingkungan } \\
\text { kerja } \\
\text { - Metode regresi } \\
\text { linier berganda }\end{array}$ & $\begin{array}{l}\text { Variabel } \\
\text { kepemimpinan } \\
\text { Tehnik } \\
\text { pengambilan } \\
\text { sampel jenuh }\end{array}$ \\
\hline 3 & $\begin{array}{l}\text { I Made Agus } \\
\text { Apriawan } \\
\text { Suamba dan } \\
\text { Ni Ketut } \\
\text { Sariyathi } \\
\text { (2014) }\end{array}$ & $\begin{array}{l}\text { Pengaruh } \\
\text { Lingkungan Kerja } \\
\text { Fisik, Promosi } \\
\text { Jabatan Dan } \\
\text { Kompensasi } \\
\text { Terhadap Kepuasan } \\
\text { Kerja. }\end{array}$ & $\begin{array}{l}\text { Lingkungan } \\
\text { Kerja Fisik, } \\
\text { Promosi } \\
\text { Jabatan, } \\
\text { Kompensasi, } \\
\text { Kepuasan } \\
\text { Kerja. }\end{array}$ & $\begin{array}{l}\text { Regresi } \\
\text { linier } \\
\text { berganda }\end{array}$ & $\begin{array}{l}\text { Lingkungan kerja fisik, promosi jabatan dan kompensasi } \\
\text { secara simultan berpengaruh signifikan terhadap } \\
\text { kepuasan kerja karyawan pada melia benoa hotel. } \\
\text { lingkungan kerja fisik, promosi jabatan dan kompensasi } \\
\text { secara parsial berpengaruh signifikan terhadap kepuasan } \\
\text { kerja karyawan pada melia benoa hotel. Variabel } \\
\text { kompensasi berpengaruh dominan terhadap kepuasan } \\
\text { kerja karyawan pada melia benoa hotel. }\end{array}$ & $\begin{array}{l}\text { - Variabel } \\
\text { lingkungan } \\
\text { kerja dan } \\
\text { kompensasi } \\
\text { - Metode regresi } \\
\text { linier berganda }\end{array}$ & $\begin{array}{l}\text { Variabel } \\
\text { promosi jabatan }\end{array}$ \\
\hline 4 & $\begin{array}{l}\text { Yopi Yunsepa } \\
(2015)\end{array}$ & $\begin{array}{l}\text { Pengaruh Lingkungan } \\
\text { Kerja, Komunikasi, } \\
\text { Kompetensi Dan } \\
\text { Kompensasi Terhadap } \\
\text { Kepuasan Kerja } \\
\text { Karyawan Pabrik Pada } \\
\text { PT Perkebunan } \\
\text { Minanga Ogan } \\
\text { Baturaja Kabupaten } \\
\text { Ogan Komering Ulu. }\end{array}$ & $\begin{array}{l}\text { Lingkungan } \\
\text { Kerja, } \\
\text { Komunikasi, } \\
\text { Kompetensi, } \\
\text { Kompensasi, } \\
\text { Kepuasan Kerja } \\
\text { Karyawan }\end{array}$ & $\begin{array}{l}\text { Regresi } \\
\text { linier } \\
\text { berganda }\end{array}$ & - & - & - \\
\hline
\end{tabular}




\section{Kerangka Pemikiran}

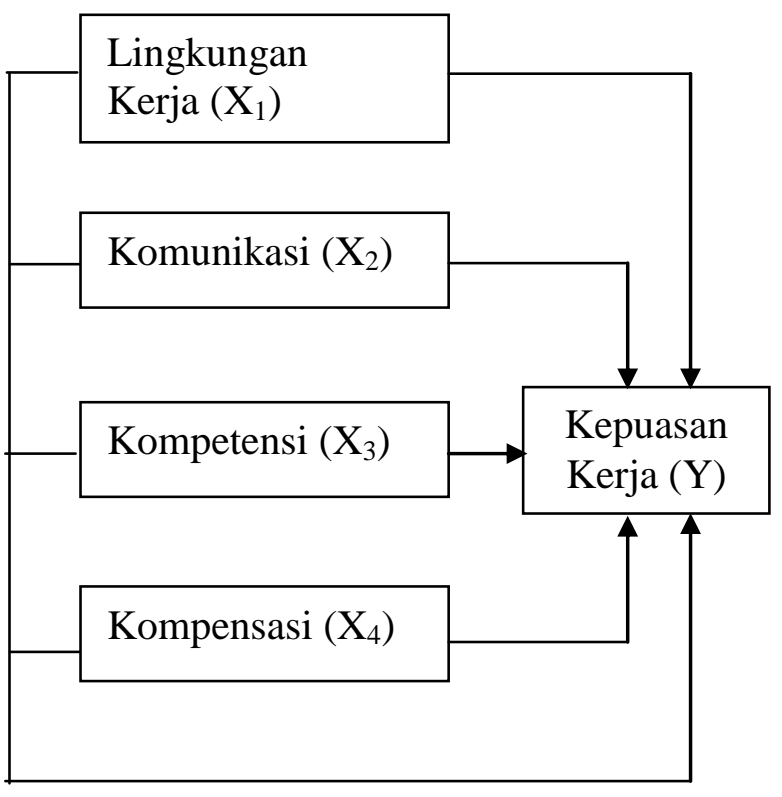

Gambar 1. Kerangka Pemikiran

\section{Hipotesis}

a. Terdapat pengaruh yang signifikan antara lingkungan kerja, komunikasi, kompetensi dan kompensasi secara bersama-sama terhadap kepuasan kerja karyawan pabrik PT Perkebunan Minanga Ogan Region SumselLampung.

b. Terdapat pengaruh yang signifikan antara lingkungan kerja terhadap kepuasan kerja karyawan pabrik PT Perkebunan Minanga Ogan Region Sumsel-Lampung.

c. Terdapat pengaruh yang signifikan antara komunikasi terhadap kepuasan kerja karyawan pabrik PT Perkebunan Minanga Ogan Region SumselLampung.

d. Terdapat pengaruh yang signifikan antara kompetensi terhadap kepuasan kerja karyawan pabrik PT Perkebunan Minanga Ogan Region SumselLampung.

e. Terdapat pengaruh yang signifikan antara kompensasi terhadap kepuasan kerja karyawan pabrik PT Perkebunan
Minanga Ogan Region SumselLampung.

\section{METODE PENELITIAN}

\section{A. Desain Penelitian}

Penelitian asosiatif yaitu penelitian yang bertujuan mengetahui hubungan antara dua variabel atau lebih (Sugiyono, 2010, p. 89). Jenis penelitian ini dapat membantu penulis untuk mengetahui pengaruh lingkungan kerja, komunikasi, kompetensi dan kompensasi terhadap kepuasan kerja karyawan pabrik SOGM PT Perkebunan Minanga Ogan Region Sumsel-Lampung.

\section{B. Data}

\section{Jenis Data}

Data yang akan digunakan dalam penelitian ini adalah data kualitatif dan kuantitatif dari hasil kuisioner yang digunakan.

\section{Sumber Data}

Data primer adalah data yang diperoleh secara langsung dari objek penelitian melalui wawancara dan kuesioner (Suharyadi dan Purwanto, 2008, p. 23). Sekunder diperoleh dari berbagai referensi yang terkait dengan penelitian ini baik berupa jurnal atau dari beberapa penelitian terdahulu yang mempunyai relevansi dengan kajian yang dilakukan.

\section{Variabel}

Penelitian ini mempelajari lima variabel, yang terdiri dari empat variabel independen $\left(\mathrm{X}_{1}, \mathrm{X}_{2}, \mathrm{X}_{3}\right.$ dan $\left.\mathrm{X}_{4}\right)$, dan satu variabel dependen (Y). Definisi operasional variabel yang digunakan dalam penelitian ini seperti ditampilkan dalam tabel dibawah ini. 
Tabel 2

\section{Definisi Operasional Penelitian}

\begin{tabular}{|c|c|c|c|c|c|}
\hline No & Variabel & Pengertian & Indikator & Skala & $\begin{array}{c}\text { Item } \\
\text { Pertanyaan }\end{array}$ \\
\hline 1 & $\begin{array}{l}\text { Kepuasan } \\
\text { Kerja (Y) }\end{array}$ & $\begin{array}{l}\text { Kepuasan Kerja adalah perasaan } \\
\text { seseorang pada pekerjaannya dan } \\
\text { merupakan suatu reaksi emosional } \\
\text { yang dapat menimbulkan perasaan } \\
\text { yang senang atau tidak senang yang } \\
\text { berhubungan dengan penghargaan. }\end{array}$ & $\begin{array}{ll}- & \text { Kepuasan dengan gaji } \\
\text { - } & \text { Kepuasan dengan promosi } \\
\text { - } & \text { Kepuasan dengan rekan } \\
& \text { kerja } \\
\text { - } & \text { Kepuasan dengan penyelia } \\
\text { - } & \text { Kepuasan dengan pekerjaaan } \\
& \text { itu sendiri }\end{array}$ & Ordinal & $\begin{array}{c}1-2 \\
3-4 \\
5-6 \\
7-8 \\
9-10\end{array}$ \\
\hline 2 & $\begin{array}{l}\text { Lingkungan } \\
\text { Kerja }\left(X_{1}\right)\end{array}$ & $\begin{array}{l}\text { Lingkungan kerja adalah segala } \\
\text { sesuatu yang ada di lingkungan } \\
\text { pekerja yang dapat mempengaruhi } \\
\text { dirinya dalam menjalankan tugas } \\
\text { yang dibebankan. }\end{array}$ & $\begin{array}{ll}\text { - } & \text { Penerangan atau cahaya } \\
\text { - } & \text { Temperatur } \\
\text { - } & \text { Sirkulasi udara } \\
\text { - } & \text { Kebisingan } \\
\text { - } & \text { Keamanan }\end{array}$ & Ordinal & $\begin{array}{l}1 \\
2 \\
3 \\
4 \\
5\end{array}$ \\
\hline 3 & $\begin{array}{l}\text { Komunikasi } \\
\left(\mathrm{X}_{2}\right)\end{array}$ & $\begin{array}{llr}\text { Komunikasi } & \text { adalah } & \text { proses } \\
\text { pemindahan pengertian } & \text { dalam } \\
\text { bentuk gagasan, informasi } & \text { dari } \\
\text { seseorang ke orang lain } & \end{array}$ & $\begin{array}{ll}\text { - } & \text { Pemahaman } \\
\text { - } & \text { Kesenangan } \\
\text { - } & \text { Pengaruh pada sikap } \\
\text { - } & \text { Hubungan yang makin baik }\end{array}$ & Ordinal & $\begin{array}{c}1 \\
2-3 \\
4 \\
5\end{array}$ \\
\hline 4 & $\begin{array}{l}\text { Kompetensi } \\
\left(\mathrm{X}_{3}\right)\end{array}$ & $\begin{array}{l}\text { Kompetensi adalah suatu } \\
\text { kemampuan untuk melaksanakan } \\
\text { atau melakukan suatu pekerjaan atau } \\
\text { tugas yang dilandasi atas } \\
\text { keterampilan dan pengetahuan serta } \\
\text { didukung oleh sikap kerja yang } \\
\text { dituntut oleh pekerjaan tersebut. }\end{array}$ & $\begin{array}{ll}\text { - } & \text { Pengetahuan yang berkaitan } \\
& \text { dengan pekerjaan } \\
\text { - } & \text { Keterampilan individu } \\
\text { - } & \text { Sikap kerja } \\
\text { - } & \text { Kepribadian }\end{array}$ & Ordinal & $\begin{array}{l}3 \\
4 \\
5\end{array}$ \\
\hline 5 & $\begin{array}{l}\text { Kompensasi } \\
\left(\mathrm{X}_{4}\right)\end{array}$ & $\begin{array}{l}\text { Kompensasi adalah faktor penting } \\
\text { yang mempengaruhi bagaimana dan } \\
\text { mengapa karyawan bekerja pada } \\
\text { suatu organisasi tertentu dan bukan } \\
\text { pada organisasi lainnya. }\end{array}$ & $\begin{array}{ll}\text { - } & \text { Kenaikan gaji } \\
\text { - } & \text { Tunjangan } \\
\text { - } & \text { Peluang promosi } \\
\text { - } & \text { Proses penilaian prestasi } \\
\text { - } & \text { Proses penentuan gaji } \\
\text { - } & \text { Proses penentuan promosi }\end{array}$ & Ordinal & $\begin{array}{l}1 \\
2 \\
3 \\
4 \\
5 \\
6\end{array}$ \\
\hline
\end{tabular}

\section{Populasi dan Sampel}

Menurut Sugiyono (2010, p. 61) Populasi adalah wilayah generalisasi yang terdiri dari objek atau subjek yang mempunyai kualitas dan karakteristik tertentu yang ditetapkan oleh peneliti untuk dipelajari dan kemudian ditarik kesimpulan. Karyawan PT Perkebunan Minanga Ogan Region Sumsel-Lampung yang berjumlah 2.324 orang, yang terdiri dari 2.083 orang karyawan perkebunan, 159 orang karyawan pabrik SOGM dan 82 orang karyawan pabrik SENM. Yang dianggap populasi dalam penelitian ini adalah semua karyawan pabrik SOGM sebanyak 159 orang. Sampel dalam penelitian ini adalah karyawan dalam lingkup pabrik SOGM sebanyak 159 responden.

\section{E. Teknik Pengumpulan Data}

Tehnik pengumpulan data dalam penelitian ini adalah dengan cara :

(1) Kuesioner, disusun berdasarkan kerangka instrument dengan alternatif jawaban :

a) Sangat Setuju dengan skor 5 
SS = Sangat Setuju

b) Setuju dengan skor 4

$\mathrm{S} \quad=$ Setuju

c) Ragu-ragu dengan skor 3

$\mathrm{R}$ = Ragu-ragu

d) Tidak Setuju dengan skor 2

TS = Tidak Setuju

e) Sangat Tidak Setuju dengan skor 1

STS $=$ Sangat Tidak Setuju

(2) Wawancara, dimaksudkan untuk menggali informasi tambahan yang diperoleh dari pihak PT Perkebunan Minanga Ogan Region Sumsel-Lampung tentang kepuasan kerja karyawan pabrik.

(3) Dokumentasi, berupa buku cetak, jurnal ilmiah, majalah-majalah dan publikasi yang berkaitan dengan perpustakaan.

\section{Metode Analisis}

\section{a) Uji Data}

\section{A. Uji Validitas}

Uji validitas digunakan untuk mengukur sah atau tidaknya suatu kuesioner. Uji Validitas adalah suatu ukuran yang menunjukkan tingkat-tingkat kevalidan atau kesahihan sesuatu instrumen (Arikunto, 1998, p. 160). Pengujian validitas dilakukan dengan menggunakan analisis korelasi product moment yang terkoreksi (corrected itemtotal correlation). Pedoman yang digunakan adalah jika hasil perhitungan $r$ hitung > $r$ tabel, maka kuesioner tersebut adalah valid.

\section{B. Uji Reliabilitas}

Uji reliabilitas adalah suatu pengukuran yang menunjukkan sejauh mana pegukuran tersebut tanpa bias (error free). Dengan kata lain reliabilitas adalah derajat ketepatan, ketelitian atau keakuratan yang ditunjukan oleh instrumen pengukuran (Malhotra, 2007, p. 95). Untuk mengetahui uji ini menggunakan nilai Cronbach Alpa, jika nilai Cronbach Alpa lebih besar 0,6 maka kuisioner tersebut dikatakan reliabel (dalam Ghozali,2005).

\section{b) Model Analisis}

Regresi linier berganda digunakan untuk menguji pengaruh beberapa variabel (X) yaitu lingkungan kerja, komunikasi, kompetensi dan kompensasi. Seperti juga pada uji-uji sebelumnya, pada uji hipotesis ini, peneliti juga menggunakan bantuan SPSS (Statistik Program for Special Science) 17.0 for Windows.

Persamaan statistiknya menggunakan regresi model linier berganda dengan model sebagai berikut (Sugiyono, 2010, p. 275):

$Y=a+b_{1} X_{1}+b_{2} X_{2}+b_{3} X_{3}+b_{4} X_{4}+e$

Keterangan :

Y : Kepuasan kerja karyawan

a : Konstanta

$b_{1}-b_{5} \quad$ : Koefisien regresi

$\mathrm{X}_{1} \quad$ : Lingkungan Kerja

$\mathrm{X}_{2} \quad$ : Komunikasi

$\mathrm{X}_{3} \quad$ : Kompetensi

$\mathrm{X}_{4} \quad$ : Kompensasi

e : Error term

\section{HASIL DAN PEMBAHASAN}

A. HASIL

1. Gambaran Umum PT Perkebunan Minanga Ogan Region SumselLampung

PT Perkebunan Minanga Ogan merupakan hasil pengembangan bisnis dari suatu perusahaan perdagangan yang bernama PT Platon. PT Platon adalah 
perusahaan yang bergerak dalam bidang ekspor komoditas kopi. Pengembangan usaha ke bidang perkebunan karena terjadinya ketidakmenentuan dalam perdagangan kopi tersebut yang mendorong pihak manajemen untuk memperluas bidang usaha perkebunan kelapa sawit, dengan prediksi bahwa dimasa yang akan datang kebutuhan akan produk olahan hasil perkebunan kelapa sawit (minyak goreng) akan terus meningkat.

PT Perkebunan Minanga Ogan yang berdiri sejak tahun 1981, pendiri dari perusahaan ini merupakan kakak beradik, Alm. Prof.Dr MR. H.Makmoen Soeleiman dan H.A. Zawawi Soeleiman,MBA. yang memiliki banyak pengalaman di bidang eksportir kopi dan merupakan salah satu eksportir kopi terkemuka.

Perjalanan pendirian PT Perkebunan Minanga Ogan, setelah di dirikan pada tahun 1981, pada tahun 1982 mulai dilakukan kegiatan pembebasan lahan dan akhir tahun 1983 dilakukan penanaman kelapa sawit perdana. Pada tahun 1987, untuk pertama kali panen kelapa sawit di mulai. Hingga saat ini telah dilakukan replanting seluas 6.000 Hektar.

Lokasi perkebunan PT Perkebunan Minanga Ogan, berada di Sumatera Selatan, tepatnya di Kabupaten Ogan Komering Ulu, Baturaja. Luas lahan yang dimiliki seluas $\pm 6.784,26$ Hektar dan kapasitas adalah 30 Ton TBS per jam. Pada tahun 2006 kapasitas pabrik telah ditingkatkan menjadi 60 Ton TBS per jam.

Seiring dengan perkembangan perusahaan, saat ini PT Perkebunan Minanga Ogan telah mengelola lahan seluas \pm 22.000 hektar, terdiri dari 14.000 hektar di Sumatera Selatan dan Lampung, 3.000 hektar di Kutai Timur, Kalimantan Timur dan 5.000 hektar daerah yang baru terbuka di Kalimantan Timur. PT
Perkebunan Minanga Ogan merupakan perkebunan kelapa sawit yang beroperasi sesuai dengan standar produksi metode perkebunan kelapa sawit, dan dikelola oleh para profesional.

\section{a. Visi dan Misi PT Perkebunan Minanga Ogan Region Sumsel- Lampung}

1). Visi

PT Perkebunan Minanga Ogan Region

Sumsel-Lampung mempunyai visi yaitu tumbuh dan berkembang bersama untuk masa depan yang lebih baik.

2). Misi

PT Perkebunan Minanga Ogan Region Sumsel-Lampung mempunyai misi yaitu mengembangkan industri kelapa sawit yang terintregrasi dan berkesinambungan melalui manajemen praktik terbaik yang peduli sosial dan lingkungan untuk mencapai kesejahteraan para stakeholder.

\section{3). Tata Nilai}

Tata nilai (values) adalah hal-hal yang harus dijunjung atau dipedomani oleh seluruh karyawan dalam melaksana-kan kegiatan berbisnis. Tata nilai ini mencakup hal-hal yang menggugah karyawan untuk memberikan kontribusi positif kepada perusahaan. Hubungan antar karyawan, hubungan dengan pihak shareholders, dan hubungan dengan stakeholders. Nilainilai tersebut yaitu morality (moralitas), enthusiame (antusias), exellent (keunggulan), growth (pertumbuhan), actualization (mewujudkan) dan honesty (kejujuran).

\section{Hasil Model Persamaan}

Berikut disajikan hasil model persamaan pengaruh lingkungan kerja, komunikasi, kompetensi dan 
kompensasi terhadap kepuasan kerja karyawan pabrik SOGM PT Perkebunan Minanga Ogan Region Sumsel-Lampung,dengan persamaan regresi

$Y=a+b_{1} X_{1}+b_{2} X_{2}+b_{3} X_{3}+b_{4} X_{4}+e$

Tabel 6

Hasil Uji Regresi

\begin{tabular}{|l|c|r|r|c|}
\multicolumn{7}{|c|}{ Model Summary $^{\text {b }}$} \\
\hline Model & $\mathrm{R}$ & R Square & $\begin{array}{c}\text { Adjusted R } \\
\text { Square }\end{array}$ & $\begin{array}{c}\text { Std. Error of the } \\
\text { Estimate }\end{array}$ \\
\hline 1 & $.559^{\mathrm{a}}$ & .313 & .295 & .6754242 \\
\hline
\end{tabular}

\begin{tabular}{|l|r|r|r|r|r|}
\hline \multirow{2}{*}{ Model } & $\begin{array}{c}\text { Unstandardized } \\
\text { Coefficients }\end{array}$ & $\begin{array}{c}\text { Standardized } \\
\text { Coefficients }\end{array}$ & & \\
\cline { 2 - 5 } & \multicolumn{1}{|c|}{ B } & Std. Error & \multicolumn{1}{c|}{ Beta } & \multicolumn{1}{c|}{$\mathrm{t}$} & Sig. \\
\hline 1 (Constant) & 1.104 & .313 & & 3.525 & .001 \\
$\quad$ Lingkungan Kerja & .145 & .066 & .153 & 2.200 & .029 \\
Komunikasi & .200 & .074 & .208 & 2.682 & .008 \\
Kompetensi & .108 & .074 & .112 & 1.465 & .145 \\
Kompensasi & .371 & .072 & .358 & 5.151 & .000 \\
\hline
\end{tabular}

Sumber : Hasil perhitungan SPSS 17.0, 2015

Berdasarkan tabel 6 di atas didapat persamaan regresi, yaitu :

$Y=1,104+0,145 X_{1}+0,200 X_{2}+0,108 X_{3}+0,371 X_{4}$

Dari persamaan regresi di atas dapat diketahui bahwa nilai konstanta sebesar 1,104, artinya jika lingkungan kerja (X1), komunikasi (X2), kompetensi (X3) dan kompensasi (X4) sama dengan nol, maka kepuasan kerja (Y) sebesar 1,104. Sedangkan koefisien regresi untuk variabel lingkungan kerja sebesar 0,145 artinya jika lingkungan kerja meningkat $100 \%$, maka kepuasan kerja juga akan meningkat sebesar 14,5\%. Koefisien regresi untuk variabel komunikasi sebesar 0,200 artinya jika komunikasi efektif tercipta $100 \%$, maka kepuasan kerja juga akan meningkat sebesar 20\%. Koefisien regresi untuk variabel kompetensi sebesar 0,108 artinya jika kompetensi meningkat $100 \%$, maka kepuasan kerja juga akan meningkat sebesar 10,8\%. Dan koefisien regresi untuk variabel kompensasi sebesar 0,371\% artinya jika kompensasi meningkat $100 \%$, maka kepuasan kerja juga akan meningkat sebesar $37,1 \%$.

Dari tabel 6 di atas juga dapat diketahui nilai koefisien korelasi (R) sebesar 0,559 ini berarti bahwa variabel lingkungan kerja (X1), komunikasi (X2), kompetensi (X3) dan kompensasi (X4) terhadap kepuasan kerja (Y) memperlihatkan hubungan yang positif, cukup kuat. Nilai koefisien determinasi (R Square) sebesar 0,313 artinya variabel lingkungan kerja, komunikasi, kompetensi dan kompensasi hanya mampu mempengaruhi variabel kepuasan kerja sebesar $31,3 \%$ sedangkan $68,7 \%$ lainnya dipengaruhi oleh variabel lain yang tidak termasuk dalam penelitian ini.

\section{B. PEMBAHASAN}

1. Pengaruh Lingkungan Kerja (X1), Komunikasi (X2), Kompetensi (X3), Kompensasi (X4) terhadap Kepuasan Kerja (Y) Karyawan Pabrik SOGM PT Perkebunan Minanga Ogan Region Sumsel-Lampung.

Berdasarkan pada uji $\mathrm{F}$ diperoleh nilai $F$ hitung sebesar 17,508 > 2,43 dan nilai Sig.F sebesar $0,000<0,05$ maka Ho ditolak dan Ha diterima. Artinya terdapat pengaruh yang signifikan antara lingkungan kerja, komunikasi, kompetensi dan kompensasi secara bersama-sama terhadap kepuasan kerja karyawan pabrik SOGM PT Minanga Ogan Region SumselLampung.

2. Pengaruh Lingkungan Kerja (X1) terhadap Kepuasan Kerja (Y) Karyawan Pabrik SOGM PT 


\section{Perkebunan Minanga Ogan Region Sumsel-Lampung.}

Hasil uji t diperoleh nilai t hitung sebesar 2,200 > 1,975 dan Sig.t 0,029 < 0,05 maka Ho ditolak dan Ha diterima. Artinya terdapat pengaruh yang signifikan antara lingkungan kerja terhadap kepuasan kerja karyawan pabrik SOGM PT Minanga Ogan Region Sumsel-Lampung.

3. Pengaruh Komunikasi (X2) terhadap Kepuasan Kerja (Y) Karyawan Pabrik SOGM PT Perkebunan Minanga Ogan Region SumselLampung.

Hasil uji $\mathrm{t}$ diperoleh nilai $\mathrm{t}$ hitung sebesar 2,682 > 1,975 dan Sig.t 0,008 < 0,05 maka Ho ditolak dan Ha diterima. Artinya terdapat pengaruh yang signifikan antara komunikasi terhadap kepuasan kerja karyawan pabrik SOGM PT Minanga Ogan Region Sumsel-Lampung.

4. Pengaruh Kompetensi (X3) terhadap Kepuasan Kerja (Y) Karyawan Pabrik SOGM PT Perkebunan Minanga Ogan Region SumselLampung.

Berdasarkan uji $\mathrm{t}$ diperoleh nilai $\mathrm{t}$ hitung sebesar $1,465<1,975$ dan Sig.t 0,145>0,05 maka Ho diterima dan Ha ditolak. Artinya tidak terdapat pengaruh yang signifikan antara kompetensi terhadap kepuasan kerja karyawan pabrik SOGM PT Minanga Ogan Region SumselLampung.

5. Pengaruh Kompensasi (X4) terhadap Kepuasan Kerja (Y) Karyawan Pabrik SOGM PT Perkebunan Minanga Ogan Region SumselLampung.

Hasil uji t diperoleh nilai t hitung sebesar 5,151 > 1,975 dan Sig.t 0,000 < 0,05 maka Ho ditolak dan Ha diterima. Artinya terdapat pengaruh yang signifikan antara kompensasi terhadap kepuasan kerja karyawan pabrikSOGM PT Minanga Ogan Region Sumsel-Lampung.

\section{IMPLIKASI}

Dalam penelitian ini membuktikan bahwa teori-teori yang digunakan sangat relevan. Hasil penelitian ini juga dapat digunakan sebagai acuan manajer dalam membuat kebijakan yang lebih baik, terutama yang berkaitan dengan lingkungan kerja, komunikasi, kompetensi dan kompensasi.

Dari hasil pembahasan dapat disimpulkan bahwa karyawan pabrik SOGM PT Perkebunan Minanga Ogan Region Sumsel-Lampung telah merasakan kepuasan kerja dimana lingkungan kerja sudah cukup baik, sehingga karyawan dapat bekerja dengan baik pula. Komunikasi antar karyawan terjalin dengan sangat baik, ini membuktikan bahwa karyawan dapat bekerjasama dalam tim, begitu pula kompetensi yang tercipta dalam tim dan pemberian kompensasi oleh pihak perusahaan sudah sesuai.

\section{SIMPULAN DAN REKOMENDASI}

\section{A. SIMPULAN}

1. Lingkungan kerja, komunikasi, kompetensi dan kompensasi berpengaruh signifikan terhadap kepuasan kerja karyawan pabrik SOGM PT Minanga Ogan Region SumselLampung.

2. Lingkungan kerja berpengaruh signifikan terhadap kepuasan kerja karyawan pabrik SOGM PT Minanga Ogan Region Sumsel-Lampung.

3. Komunikasi berpengaruh signifikan terhadap kepuasan kerja karyawan pabrik SOGM PT Minanga Ogan Region Sumsel-Lampung.

4. Kompetensi tidak berpengaruh signifikan terhadap kepuasan kerja 
karyawan pabrik SOGM PT Minanga Ogan Region Sumsel-Lampung.

5. Kompensasi berpengaruh signifikan terhadap kepuasan kerja karyawan pabrik SOGM PT Minanga Ogan Region Sumsel-Lampung.

\section{B. REKOMENDASI}

1. Pimpinan pabrik SOGM PT Minanga Ogan Region Sumsel-Lampung diharapkan memiliki inovasi-inovasi baru yang dapat meningkatkan kepuasan kerja karyawan pabrik.

2. Pihak perusahaan sebaiknya lebih memperhatikan lingkungan kerja, terutama tentang kebisingan di tempat kerja, dengan cara membuat ruangan kerja karyawan yang kedap suara, sehingga karyawan dapat lebih berkonsantrasi dalam bekerja dan akan lebih meningkatkan kepuasan kerja karyawan pabrik.

3. Pimpinan pabrik SOGM PT Minanga Ogan Region Sumsel-Lampung agar tetap menjaga komunikasi yang baik dengan karyawan, baik pada waktu jam kerja maupun di luar jam kerja, sehingga kepuasan kerja karyawan pabrik akan bisa maksimal.

4. Pimpinan pabrik SOGM PT Minanga Ogan Region Sumsel-Lampung agar lebih memperhatikan dan meningkatkan kompetensi karyawan, agar dapat menempatkan karyawan yang tepat pada posisi yang tepat pula, sehingga kepuasan kerja karyawan pabrik akan meningkat.

5. Pimpinan pabrik SOGM PT Minanga Ogan Region Sumsel-Lampung agar lebih meningkatkan pemberian kompensasi dengan lebih memperhatikan dari segi tunjangan, bonus dan fasilitas yang diberikan guna mencukupi kebutuhan karyawan, sehingga dapat meningkatkan kepuasan kerja karyawan pabrik.

\section{Daftar Pustaka}

Ali, Baroroh. 2013. Analisis Multivariat dan Time Series dengan SPSS 21. Jakarta. Kompas Gramedia.

Ali, Raja Muhammad, Faraz Ahmed Wajidi. 2013. The Factores Influencinged Job Satisfaction's Public Healthcare Sector of Pakistan. Journal of Management and Businesses. 13(8). pp: 60 -66.

Arikunto, Suharsimi. 1998. Prosedur Penelitian Suatu Pendekatan Praktek. Jakarta.Rineka Cipta.

Astuti, Sri Rahayu Tri. 2006. Analisis Faktor-Faktor Yang Mempengaruhi Kepuasan Kerja Dan Kinerja Tenaga Penjualan (Studi Kasus Tenaga Penjualan PT Columbia Semarang). Jurnal Universitas Diponegoro, Vol.10 No.2, Hal.123

Dole, Carol and Schroeder, Richard G., 2001, The Impact of Varios Factors on the Personality, Job Satisfaction and Turn Over Intentions of Profesional Accountants. Managerial Auditing Journal, Vol. 16 No.4 pp 234-245.

Douglas,B. Currivan. 2000. The Causal Order Of Job Satisfaction And Organizational Commitment In Models of employee Turnover. University of Massachussets, Boston ,MA, USA.

Dwi Priyanto. 2008. Mandiri Belajar SPSS Untuk Analisis dan Uji Statistik. Jakarta: Gramedia Pustaka Utama.

Gorda, I Gusti Ngurah. 2004. Manajemen Sumber Daya Manusia. Edisi 
Revisi. Denpasar: Astabrata Bali bekerjasama dengan STIE Satya Dharma Singaraja.

Hani Handoko T., 2001. Manajemen Personalia dan Sumber Daya Manusia. Edisi kedua. Yogyakarta : BPFE.

Husein Umar. 2008. Metode Penelitian untuk Skripsi dan Tesis Bisnis. Jakarta: PT Raja Grafindo Persada.

I Gede Diatmika Paripurna. 2012. Pengaruh Kepemimpinan, Lingkungan Kerja Dan Komunikasi Terhadap Kepuasan Kerja Karyawan. Jurnal Fakultas Ekonomi Universitas Udayana (Unud), Bali, Indonesia. Vol 2, No 5 (2013)

Imam Ghozali. 2005. Aplikasi Multivariance dengan Program SPSS. Yogjakarta: Semarang: Universitas Diponegoro.

I Made Agus Apriawan Suamba dan Ni Ketut Sariyathi. 2014. Pengaruh Lingkungan Kerja Fisik, Promosi Jabatan Dan Kompensasi Terhadap Kepuasan Kerja. Penelitian ini dilakukan pada Melia Benoa Hotel. Jurnal Jurnal Fakultas Ekonomi dan Bisnis Universitas Udayana (Unud), Bali, Indonesia. Vol 4, No 1 (2015).

Malayu S.P. Hasibuan, 2005. Manajemen Sumber Daya Manusia. Bumi Aksara. Jakarta

Mangkunegara Anwar Prabu, 2005. Manajemen Sumber Daya Manusia Perusahaan, Cetakan Keenam, PT. Remaja Rosdakarya, Bandung.

Mangkunegara Anwar Prabu, 2005. Perilaku dan Budaya Organisasi, Cetakan Pertama, PT. Refika Aditama, Bandung.
Mokaya, Samuel Obino, Musau, Jacqueline Lovega, Wagoki, Juma dan Karanja, Kabare. 2013. Effects of Organizational Work Conditions on Employee Job Satisfaction in the Hotel Industry in Kenya. International Journal of Arts and Commerce. Vol. 2 No. 2.

Martoyo, Susilo. 2007. Manajemen Sumber Daya Manusia. Edisi Kelima. BPFE-Yogyakarta.

Ni Putu Intan Ratnasari dan A.A Sagung Kartika Dewi. 2013. Pengaruh Motivasi, Lingkungan Kerja Fisik Dan Kepemimpinan Terhadap Kepuasan Kerja Karyawan. Jurnal Fakultas Ekonomi dan Bisnis Universitas Udayana (Unud), Bali, Indonesia. Vol 3, No 7 (2014).

Nitisemito, Alex. 2002. Manajemen Sumber Daya Manusia. Cetakan Kesembilan. Edisi ke Empat. Jakarta: Ghalia Indonesia.

Robbins, Stephen P., 2001, Organizational Behavior, Upper Saddle River, New Jersey Prentice- Hall Inc.

Robbins Stephen P., 2002. Essentials of Organizational Behavior (Terjemahan), Edisi Kelima, Penerbit Erlangga, Jakarta.

Robbins, Stephen, 2006, Perilaku Organisasi, Prentice Hall, edisi kesepuluh

Sedarmayanti. 2001. Sumber Daya Manusia dan Produktivitas Kerja. Bandung: Mandar Maju. 